\title{
Evaluating applicants' credit capability for banking facilities by qualitative and operational indicators
}

\author{
Somayeh Yarifard $^{a^{*}}$ and Sahar Ojaghi
}

${ }^{a}$ Masters Student, Department of Management, Central Branch, Islamic Azad University, Tehran, Iran ${ }^{b}$ Masters Student, Department of Management, Central Branch, Islamic Azad University, Tehran, Iran

\begin{tabular}{l}
\hline C H R O N I C L E \\
\hline Article history: \\
Received December 5, 2015 \\
Received in revised format \\
March 162016 \\
Accepted May 282016 \\
Available online \\
May 30 2016 \\
\hline Keywords: \\
Bank Mellat \\
Credit risk \\
Loan
\end{tabular}

\begin{abstract}
A B S T R A C T
Consumer credit risk assessment involves the implementation of risk assessment techniques to manage a borrower's account from the event of pre-screening a potential application through to the management of the account during its life-cycle and possible write-off. This paper presents an empirical investigation to study the relationship between 13 different factors such as credit history, applications' educational and management skills, etc. and credit risk. The study selects the profiles of 380 applicants who received loans from one of Iranian banks named Bank Mellat in city of Tehran, Iran over the period 2010-2011. Using Pearson correlation, the study has determined a meaningful relationship between applicants' profiles including credit history, business characteristics, personal characteristics, etc. and credit risk.
\end{abstract}

\section{Introduction}

Consumer credit risk assessment involves the implementation of risk assessment techniques to manage a borrower's account from the event of pre-screening a potential application through to the management of the account during its life-cycle and possible write-off (Saunders et al., 2006; Crook et al., 2007). Risk assessment of financial intermediaries is an area of renewed interest due to the financial crises of the 1980's and 90's. (Galindo \& Tamayo, 2000). Behr and Güttler (2007) estimated a logit scoring technique to determine the probability of default by German small and medium-sized enterprises (SMEs) based on a unique data set on SME loans in Germany. The scoring model assists SMEs to provide knowledge about their default risk used to estimate their risk sufficient cost of debt, which can be used to detect hold-up problems that German SMEs might be faced with in their bank relationships. It also helps them monitor their bank's pricing attitude and reduces information asymmetries between lenders and borrowers. Oreski et al. (2012) studied the extent to which the total data, owned by a bank, could be a basis for forecasting the borrower's capability to repay the loan. They proposed a feature selection to locate an optimum feature subset, which enhances the classification precision of neural network classifiers and using some experiments on the credit dataset, they managed to collect at a 
Croatian bank to evaluate the precision of their model. They reported that the hybrid system with genetic algorithm could be competitive and be used as feature selection technique to detect the most substantial features in determining risk of default.

Credit risk prediction models look for predicting quality factors such as whether an individual will default on a loan or not, which can be considered as a type of machine learning (ML) issue. Recently, the implementation of ML algorithms has become a popular method for solving different risk problems including credit risk prediction. Twala (2010) explored the forecasted behavior of five classifiers for various kinds of noise in terms of credit risk prediction accuracy, and how such accuracy could be improved by applying classifier ensembles. They offered results on four credit datasets and compared their results with the performance of each individual classifier on predictive accuracy at various attribute noise levels.

Min and Lee (2008) proposed a data envelopment analysis (DEA) for credit scoring and applied the method for current financial data of external audited 1061 manufacturing companies in Korea. Based on some financial ratios, the methodology could synthesize a company's overall performance into a single financial credibility score. Carling et al. (2007) forecasted a duration model to describe the survival time to default for borrowers in the business loan portfolio of a Swedish bank over the period 1994-2000. The model considered both firm-specific characteristics, such as accounting ratios and payment behavior, loan-related data, and the prevailing macroeconomic conditions. They reported that the output gap, the yield curve and consumers' expectations of future economic development had substantial explanatory power for the default risk of companies. They also compare their model with a frequently applied model of firm default risk that conditions only on firm-specific information. Their comparison indicated that while the latter model could make a reasonably precise ranking of firms' according to default risk, the model, by taking macro conditions into account, was also able to consider for the absolute level of risk.

Gordy (2003) explained that ratings-based capital rules, including both the current Basel Accord and its proposed revision, could be reconciled with the general class of credit value-at-risk models. Demerjian et al. (2012) investigated the relationship between managerial ability and earnings quality and reported that earnings quality was positively related to managerial ability. Specifically, more able managers, in their survey, were associated with fewer subsequent restatements, higher earnings and accruals persistence, lower errors in the bad debt provision, and higher quality accrual estimations. Subrahmanyam et al. (2016) applied credit default swaps (CDS) trading data to show that the credit risk of reference companies, reflected in rating downgrades and bankruptcies, could possibly increase based on the inception of CDS trading. In addition, distressed companies were more likely to file for bankruptcy if they were linked to CDS trading.

Bedendo and Colla (2015) investigated the effect of sovereign risk on the credit risk of the non-financial corporate sector in the Eurozone using credit default swap data. They explained that an increase in sovereign credit spreads was related to a statistically and economically substantial increase in corporate spreads and, hence, firms' borrowing expenses. A deterioration in a country's credit quality may influence on adversely companies, which are more likely to be contributed from government aid, those whose sales were more focused on the domestic market, and those that depend on bank financing.

Chaibi and Ftiti (2015) implemented a dynamic panel data method to study the determinants of nonperforming loans (NPLs) of commercial banks in a market-based economy, represented by France, compared with a bank-based economy, represented by Germany, during 2005-2011. They reported that both economies belong to the same euro area and compared with Germany, the French economy was more susceptible to bank-specific determinants. 


\section{The proposed study}

In this paper, we present an empirical investigation to study the relationship between bank customers' credit history and 13 different characteristics. The survey applies for both individuals and business type customers. We have defined a dummy variable as dependent variable, which is one if customer has some record of delay on payments of loans received and zero, otherwise. The study also considers 13 different customers' characteristics as follows,

1. History of transactions or the period of transactions with bank,

2. Having business certificate, credit card, line of credit, etc.,

3. Credibility of customers' real state, business ownership, etc.,

4. Present tangible and intangible assets,

5. Intensity of labor force used for business activities,

6. Number of employees,

7. The quality of labor force according to age, the labor force is employed in the number of employees by the age range,

8. The quality of labor force according to gender, status of the labor force is employed in the number of employees by the sex separation,

9. The quality of labor force based on education, status of the labor force is employed in the number of employees according to their academic documents,

10. The outstanding debts, certain or probable debt of applicant in the banking system that is due date but not paid, which is given to the Central Bank of the Islamic Republic of Iran through bank inquiry about banking facilities and foreign exchange obligations have not played are measurable,

11. The dishonored check history, the experience of the dishonored check history of banking facilities applicants, which is possible by the bank inquiry from the Central Bank of the Islamic Republic of Iran for opening current account and is measurable,

12. The management competence based on education, i.e. the capability to manage the use of limited resources to achieve profitability objectives and activities, which are evaluated by different parameters such as settling account, the amount of relevant occupation experience, education and etc.

13. Management job experience and overall qualification.

The population of this survey includes 39,114 credit files from July, 2010 to June, 2011 associated with Bank Mellat located in city of Tehran, Iran. There were 316 branches in city of Tehran and the proposed study of this paper has used a clustering system and divided them into six categories. The sample size is calculated as follows,

$$
n=\frac{N \times z_{\alpha / 2}^{2} \times p \times q}{\varepsilon^{2} \times(N-1)+z_{\alpha / 2}^{2} \times p \times q},
$$

where $N$ is the population size, $p=1-q$ represents the yes/no categories, $z_{\alpha / 2}$ is CDF of normal distribution and finally $\varepsilon$ is the error term. Since we have $p=0.5, z_{\alpha / 2}=1.96$ and $N=39114$, the number of sample size is calculated as $n=380$. Fig. 1 presents personal characteristics of the participants. 


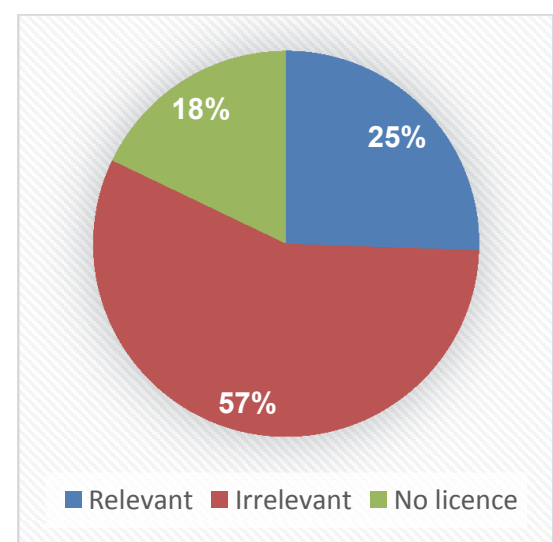

Activity license

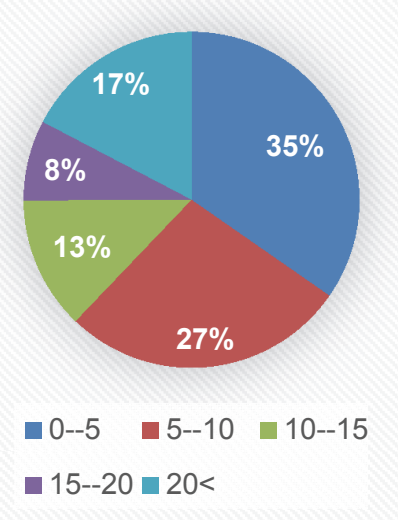

Activity history

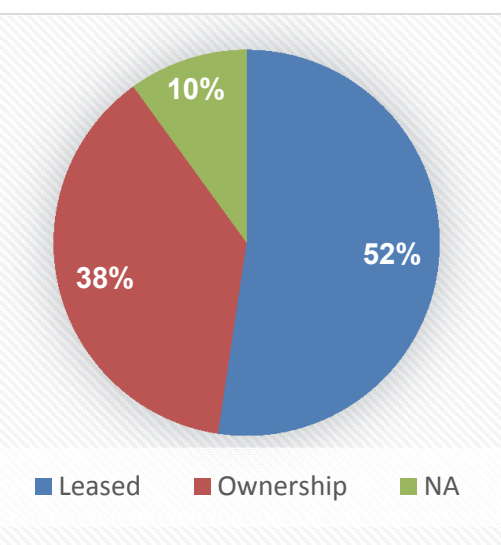

Expertise

Fig. 1. Personal characteristics of the participants

As we can observe from the results of Fig. 1, only $25 \%$ of the people used bank facilities maintained an appropriate license which was associated with their business activities and the others either did not have such documents or presented irrelevant documents. In our survey, most participants had, at least, 5 years of business activities and nearly half of them did not own their properties. Also, in our survey, $58 \%$ of the participants claimed their business was not capital intensive while $51 \%$ of them also stated that their business was not even labor intensive. In fact, $61 \%$ of the participants requested loan for business activities with fewer than 20 people and only $9 \%$ of them had businesses with more than 100 workers. Also, in our sample, nearly, $60 \%$ of the customers claimed to hire middle aged workers. The survey has appeared to be associated with male oriented business activities since $87 \%$ of the applicants stated they hired men for their business activities where $77 \%$ of them hold some university degrees. In terms of credit history, while $88 \%$ of the participants in our survey did not have any other liabilities and $90 \%$ of them did not have any bad credit. In our survey, nearly half of the loan applicants had some related university background with at least 5 years of job experiences.

\section{The results}

The implementation of Kolmogorov-Smirnov has indicated that the data were normally distributed and we may use parametric tests to examine the relationship between customers' credit history and 13 characteristics. Table 1 demonstrates the results of the implementation of Pearson correlation.

\section{Table 1}

The summary of Pearson correlation

\begin{tabular}{lcccc}
\hline Variable & error & Sig. & $\begin{array}{c}\text { Correlation } \\
\text { coefficient }\end{array}$ & $\begin{array}{c}\text { Hypothesis } \\
\text { confirmation }\end{array}$ \\
\hline Activity history \& credit risk & 0.05 & 0.000 & 0.218 & Confirmed \\
Activity license \& credit risk & 0.05 & 0.000 & 0.604 & Confirmed \\
Ownership status \& credit risk & 0.05 & 0.005 & 0.143 & Confirmed \\
Capital-intensive \& credit risk & 0.05 & 0.004 & -0.148 & Confirmed \\
Labor-intensive \& credit risk & 0.05 & 0.000 & -0.188 & Confirmed \\
Quantity of labor force \& credit risk & 0.05 & 0.000 & 0.443 & Confirmed \\
Quality of labor force based on age \& credit risk & 0.05 & 0.000 & 0.599 & Confirmed \\
Quality of labor force based on education \& credit risk & 0.05 & 0.000 & 0.593 & Confirmed \\
Quality of labor force based on gender \& credit risk & 0.05 & 0.719 & 0.18 & Not confirmed \\
Outstanding debt \& credit risk & 0.05 & 0.000 & 0.204 & Confirmed \\
Dishonored check \& credit risk & 0.05 & 0.000 & 0.238 & Confirmed \\
Management competence- relevant education \& credit risk & 0.05 & 0.000 & 0.409 & Confirmed \\
Management competence - experience history \& credit risk & 0.05 & 0.000 & 0.519 & Confirmed \\
\hline
\end{tabular}


According to the results of Table 1, except one case i.e. workers' gender, there were some meaningful positive/negative relationships between credit risk and items explained when the level of significance was one percent.

\section{Conclusion}

In this survey, we have presented an empirical investigation to study the effects of different factors, which could influence on credit risk of clients received loans from an Iranian bank. The study has determined 13 different factors associated with either personal characteristics of the loan applications such as educational background, management skills, etc. or business components such as assets, equipment, workers' age, etc. Using Pearson correlation, the study has detected a positive and meaningful relationship between credit risk and applicants' credit history, ownership status while there were negative and meaningful relationship between intensity of business type and credit history. Nevertheless, the study did not find any meaningful relationship between worker's gender and credit risk. The results of this study are somewhat consistent with other findings reported on the literature (Yi et al., 2012; Zhang et al., 2016).

\section{Acknowledgment}

The authors would like to thank the anonymous referees for constructive comments on earlier version of this paper. We are also delighted for the supports received from Bank Mellat officials on sharing the information of their clients' loan applications.

\section{References}

Bedendo, M., \& Colla, P. (2015). Sovereign and corporate credit risk: Evidence from the Eurozone. Journal of Corporate Finance, 33, 34-52.

Behr, P., \& Güttler, A. (2007). Credit risk assessment and relationship lending: An empirical analysis of German small and medium-sized enterprises. Journal of Small Business Management, 45(2), 194213.

Carling, K., Jacobson, T., Lindé, J., \& Roszbach, K. (2007). Corporate credit risk modeling and the macroeconomy. Journal of Banking \& Finance, 31(3), 845-868.

Chaibi, H., \& Ftiti, Z. (2015). Credit risk determinants: Evidence from a cross-country study. Research in International Business and Finance, 33, 1-16.

Gordy, M. B. (2003). A risk-factor model foundation for ratings-based bank capital rules. Journal of Financial Intermediation, 12(3), 199-232.

Crook, J. N., Edelman, D. B., \& Thomas, L. C. (2007). Recent developments in consumer credit risk assessment. European Journal of Operational Research, 183(3), 1447-1465.

Demerjian, P. R., Lev, B., Lewis, M. F., \& McVay, S. E. (2012). Managerial ability and earnings quality. The Accounting Review, 88(2), 463-498.

Galindo, J., \& Tamayo, P. (2000). Credit risk assessment using statistical and machine learning: basic methodology and risk modeling applications. Computational Economics, 15(1-2), 107-143.

Min, J. H., \& Lee, Y. C. (2008). A practical approach to credit scoring. Expert Systems with Applications, 35(4), 1762-1770.

Oreski, S., Oreski, D., \& Oreski, G. (2012). Hybrid system with genetic algorithm and artificial neural networks and its application to retail credit risk assessment. Expert systems with applications, 39(16), 12605-12617.

Saunders, A., Cornett, M. M., \& McGraw, P. A. (2006). Financial institutions management: A risk management approach (Vol. 8). McGraw-Hill/Irwin.

Subrahmanyam, M. G., Tang, D. Y., \& Wang, S. Q. (2016). Does the tail wag the dog? The effect of credit default swaps on credit risk. In Development in India (pp. 199-236). Springer India.

Twala, B. (2010). Multiple classifier application to credit risk assessment.Expert Systems with 
Applications, 37(4), 3326-3336.

Yi, G., Lei, H., \& Ziqiang, L. (2015). Port customer credit risk prediction based on Internal and external information fusion. Open Cybernetics \& Systemics Journal, 9, 1323-1328.

Zhang, F., Tadikamalla, P. R., \& Shang, J. (2016). Corporate credit-risk evaluation system: Integrating explicit and implicit financial performances.International Journal of Production Economics, 177, 77-100. 